\title{
Voltage Control and Braking System of a DFIG during a Fault
}

\author{
Rabin Mahat ${ }^{a}$, Khagendra B. Thapa ${ }^{b}$, Sudip Lamichhane, Sudeep Thapaliya, Sagar Dhakal \\ Department of Electrical Engineering, Pulchowk Campus, Institute of Engineering, Tribhuvan University, Nepal \\ Corresponding Authors: ${ }^{a}$ rabinmahat 786@gmail.com, ${ }^{b}$ khagen@pcampus.edu.np
}

Received: 2020-08-31

Revised: 2021-01-23

Accepted: 2021-01-30

\begin{abstract}
:
This paper describes a voltage control scheme of a doubly fed induction generator (DFIG) wind turbine that can inject more reactive power to the grid during a fault so as to support the grid voltage. To achieve this, the coordinated control scheme using both rotor side converter (RSC) and grid side converters (GSC) controllers of the DFIG are employed simultaneously. The RSC and GSC controllers employ PI controller to operate smoothly. In the voltage control mode, the RSC and GSC are operated. During a fault, both RSC and GSC are used simultaneously to supply the reactive power into the grid (main line) depending on voltage dip condition to support the grid voltage. The proposed system is implemented for single DFIG wind turbine using MATLAB simulation software. The results illustrate that the control strategy injects the reactive power to support the voltage stability during a fault rapidly. Also, the braking system is designed to protect the wind turbine system from over speed. For this purpose, the braking resistors are being used.
\end{abstract}

Keywords: Voltage control, Braking System, DFIG, RSC, GSC

\section{Introduction}

Among many renewable energies, wind energy is one of them. It is generated from air current. This kinetic energy is converted into useful power through wind turbines. Furthermore, transmission lines help to supply power for mills, home, hospitals, farm, school, industries and many more business applications on different scales, [1, 2]. It is also the source for generating sustainable, clean and green energy. Nowadays, wind energy is considered as one of the fastest growing sources of power generation.

In this project we are generating electricity with the help of DFIG. A widely used DFIG system used the power electronics to control the rotor currents for the maximum energy generation by varying the speed. There are many advantages of DFIG over other generators as they are economic, can control speed and have low power loss. Since the power control of the stator line can be controlled from rotor line where only about $30 \%$ of the power flows, power converters with low ratings is used.

The DFIG system is popular system that is used worldwide over others generators [1]. Doubly-fed generator rotors are typically wound rotor type with 2 to 3 times the noumber of turns of the stator [3]. They are used due to their low inverter cost, their ability of generating useful power, mechanically and electrically simpler than other generator types. Here, drives turbines drive on $\mathrm{AC} / \mathrm{AC}$ converter that converts $\mathrm{AC}$ to $\mathrm{DC}$ with a rectifier and back to $\mathrm{AC}$ with an inverter. These converters are also called as back-to-back converters. The objective of these converters is to match the frequency and phase of the grid. When the system goes into major fault like failure of a grid or a high hurricane, it is necessary to break the system in order to protect the wind turbine from speeding and converters from high heat due to excessive rotor current. Hence this project also aims to design a proper braking system.

\subsection{Braking of wind turbine}

Grid failure is not the most common in power system network. But when it occurs, the speed of the DFIG rises to a tremendously high value. This can be dangerous and can cause damage to the blades as well causes other mechanical problems. In order to avoid such situation, the speed has to be limited to a safer value during grid failure through braking. Two types of 
braking are designed in our project Electrical and Mechanical braking.

\subsubsection{Electrical Braking}

This can be done by using a power resistor called Braking Resistor. The excess power is dissipated in the resistor limiting the overspeed.

The ability of braking resistors to dissipate heat can be utilized to decrease the performance of a mechanical system. This energy is dissipated by using a Braking resistor. Since, we know that braking resistors have the properties of relatively low ohmic values and a high-power rating. So, these resistors are popular solution. For creating a safe distance between different parts, resistors are covered in a frame. The cooling fins, fans or even water cooling can be used to increase the dissipation capability. It has the advantages of less service required and higher reliability is ensured.

\subsubsection{Mechanical Braking}

Mechanical braking normally used for wind turbines are disc brakes. These disc brakes used the calipers for producing friction. The generated friction helps in slow down the rotation of turbine shaft or to reduce the stationary movement. The energy of motion is transferred into waste heat that must be dispersed. We can employ these above brakes in different positions of the shafts. We can employ on the high-speed and low speed shaft and also in between them.

The braking torque has to be of high value in case of lowspeed shaft brake. The position in between the gearbox and generator is the most cost-effective one. The gear ration can be increased to reduce the output torque.

This is the simple figure of a DFIG based wind turbine. During a fault, the RSC and GSC controllers regulate the system by injecting active and reactive power. It also balances oscillation torque and controls MPPT in the system. Here, pitch controller [7] is used to control the pitch angle of the wind turbine. RSC and GSC controllers inject their pulse signals to the RSC and GSC respectively. Step up transformer is used to step the generating voltage to connect with the grid. These all actions are performed in that of rotor side of the machine. Stator side of the machine is directly connected with the transformer. Rotor side of the machine is connected to the transformer through converters.

\section{Control of DFIG}

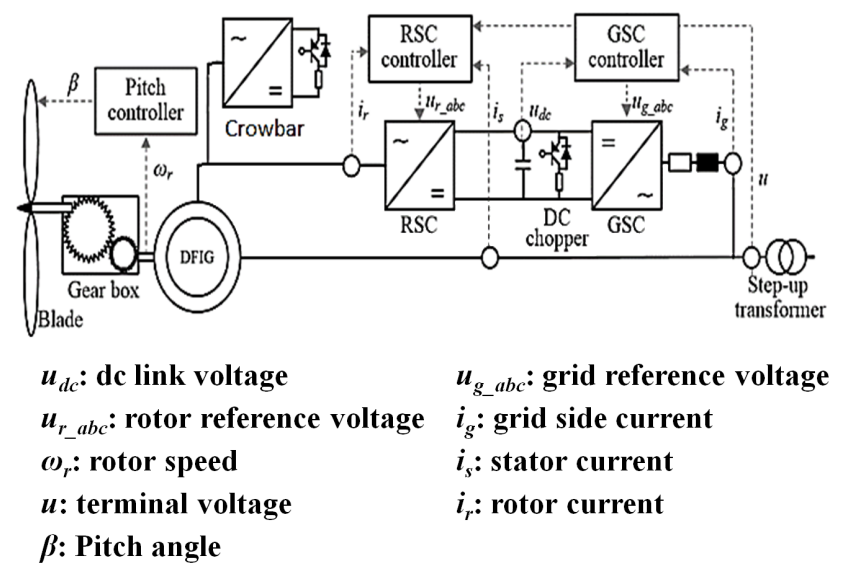

Figure 1: Layout of a DFIG based wind turbine

Here, rotor allows bidirectional power flow from and to the grid. Stator allows only unidirectional power flow. At sub-synchronous speed, rotor acts as a motor and absorbs the power coming from grid. But at supersynchronous speed, rotor acts as a generator. Now, the power will be delivered from both rotor and stator side to the main line system.

The voltage at stator and rotor of DFIG is given as [12]:

$$
\begin{aligned}
& V_{s}=R_{s} \cdot I_{s}+L_{s} \frac{d I_{s}}{d t}+L_{m} \frac{d I_{r}}{d t}+j \omega_{1} \cdot \varphi_{s} \\
& V_{r}=R_{r} \cdot I_{r}+L_{r} \frac{d I_{r}}{d t}+L_{m} \frac{d I_{s}}{d t}+j \omega_{\text {slip }} \cdot \varphi_{r}
\end{aligned}
$$

where,

$L_{s}=$ inductance of stator,

$L_{m}=$ magnetizing inductance

$L_{r}=$ inductance of rotor

$I_{s}=$ stator current $I_{r}=$ rotor current

$\omega_{1}=$ angular speed at stator

$\omega_{\text {slip }}=$ angular speed at slip

$\varphi_{s}=$ stator flux

$\varphi_{r}=$ rotor flux

The relations between rotor current with the active and reactive power of stator is given below as [12]:

$$
P_{s}=\frac{3}{2} \omega_{s} \frac{L_{m}^{2}}{L_{s}} I_{m o} \cdot I_{r q}
$$




$$
Q_{s}=\frac{3}{2} \omega_{s} \frac{L_{m}^{2}}{L_{s}}\left(I_{r d}-I_{m o}\right) \cdot I_{m o}
$$

where,

$P_{s}=$ stator active power

$Q_{s}=$ stator reactive power

$I_{d r}=\mathrm{d}$-axis rotor current

$I_{q r}=\mathrm{q}$-axis rotor current

From equation (3) and (4), it can be inferred that $I_{r q}$ is responsible to regulate the stator active power whereas; $I_{r d}$ is responsible to regulate the stator reactive power. The $I_{r q}$ reference can be obtained from optimal power tracking curve provides whereas $I_{r d}$ reference can be obtained from AC voltage controller. The equivalent stator magnetizing current $I_{m o}$ is defined as:

$$
\varphi_{s}=L_{s} \cdot I_{s}+L_{r} \cdot I_{r}=L_{s} \cdot I_{m o}
$$

\section{Wind Turbine Model}

The accessible power in the air $\left(P_{\text {air }}\right)$ is given by:

$$
P_{\text {air }}=\frac{1}{2} * \rho A v^{3}
$$

where,

$\rho=$ density of air $\left(\mathrm{kg} / \mathrm{m}^{3}\right)$

$\mathrm{A}=$ area swept by the blades $\left(m^{2}\right)$

$v=$ wind $\operatorname{speed}(\mathrm{m} / \mathrm{s})$

The mechanical input power $\left(P_{\text {mech }}\right)$ is expressed as:

$$
P_{\text {mech }}=\frac{1}{2} * \rho A C_{p}(\lambda, \beta) v^{3}
$$

where, $C_{p}=$ power coefficient of the wind generator, it has no unit.

It depends on both tip speed ratio $(\lambda)$ and blade pitch angle $(\beta)$.

Tip speed ratio (T.S.R), $\lambda$ is expressed as:

$$
\lambda=\frac{\omega_{r} R}{v}
$$

where, $\omega_{r}=$ rotational speed of turbine in $\mathrm{rad} / \mathrm{s}$

$\mathrm{R}=$ radius of wind turbine rotor in $\mathrm{m}$.

Maximum power will be extracted from the wind if power cofficient constant is maximum. We have to keep the value of T.S.R at its optimum value. From Figure 2, maximum power in the maximum power point tracking (MPPT) mode can be shown and given by:

$$
P_{\text {max }}=\kappa_{\text {opt }} \omega_{o p t}^{3}
$$

where,

$\omega_{\text {opt }}=$ optimum rotor speed

$\kappa_{\text {opt }}=$ optimum constant.

The reference value of the machine side converter (MSC) for the MPPT mode control is expressed as:

$$
P_{r e f}=K_{g} \omega_{r}^{3}
$$

where, $K_{g}=$ function of the parameter like as gear-ratio(N), blade profile and length,etc.

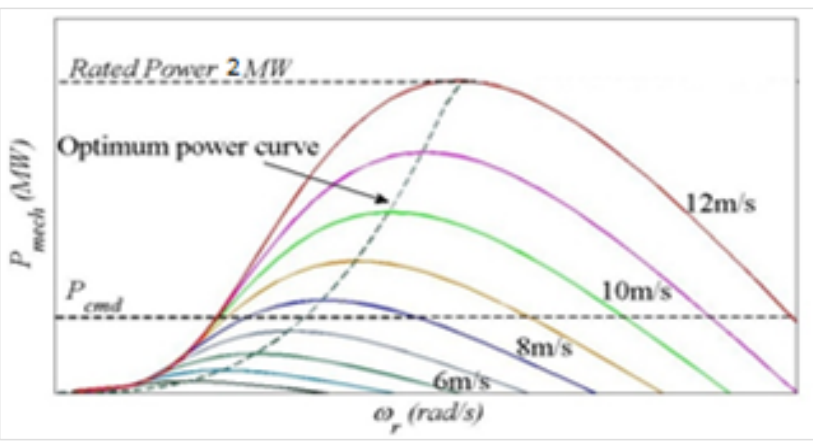

Figure 2: Characteristics curve for the active power and rotor speed of a variable speed wind turbine

Figure 3 shows the complete DFIG controller. It includes two types of controller. They are RSC and GSC controller. For controlling the stator side voltage and that of active power, RSC controller is employed. Also, GSC controller is for controlling dc-link voltage and the reactive power. The reactive power will be injected to the grid to support the voltage. DC chopper is placed in between back-to-back converters to regulate the increased dc-link voltage. 


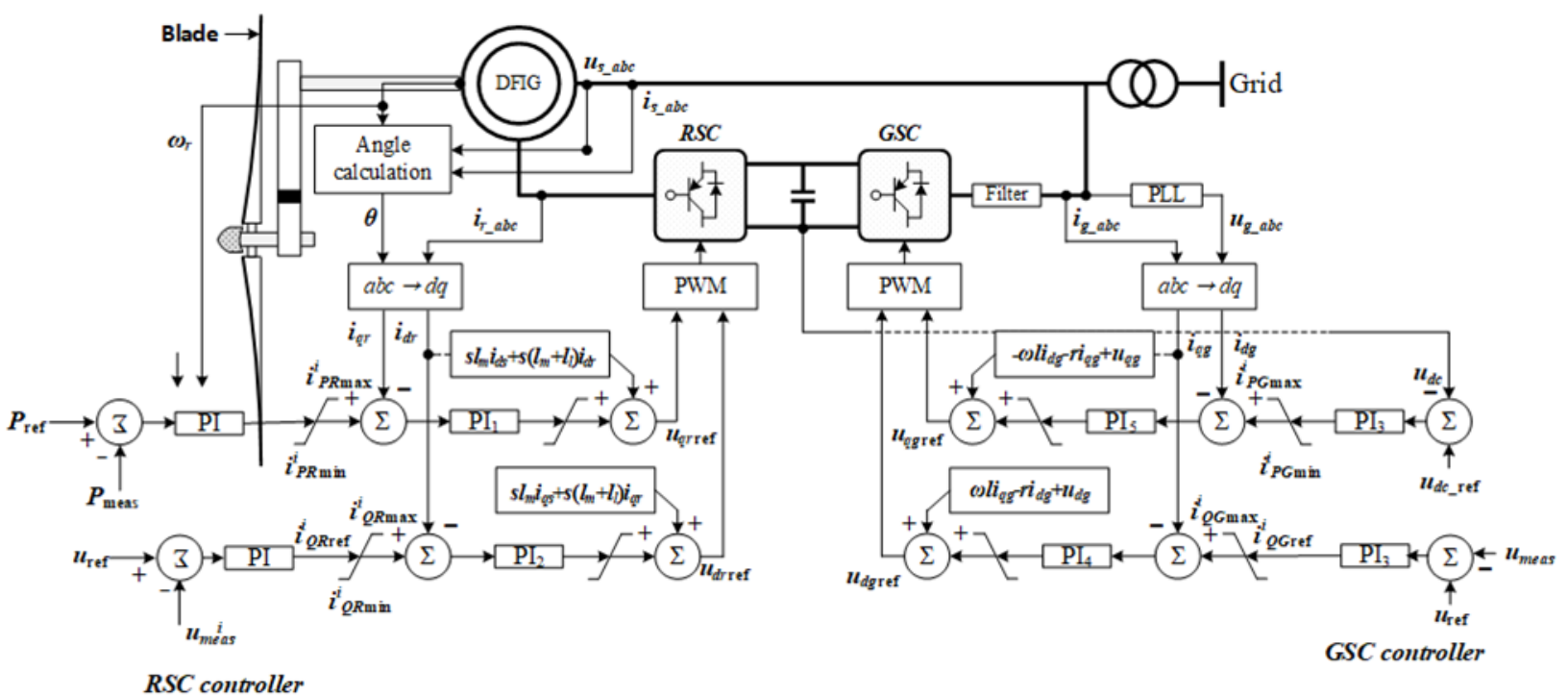

Figure 3: DFIG controller

Table 1: Nomenclature

\begin{tabular}{ll}
\hline$i_{g-a b c}$ & instantaneous GSC current \\
\hline$i_{r \_a b c}$ & instantaneous rotor current \\
\hline$u_{q r r e f}$ & reference q-axis rotor voltage \\
\hline$u_{d r r e f}$ & reference d-axis rotor voltage \\
\hline$u_{q g r e f}$ & reference q-axis GSC voltage \\
\hline$u_{d g r e f}$ & reference d-axis GSC voltage \\
\hline$\omega_{r}$ & rotor angular frequency \\
\hline$u_{d c \_r e f}$ & reference dc link voltage \\
\hline$P_{\text {meas }}$ & measured power \\
\hline$i_{d g}$ & d-axis grid side current \\
\hline$\theta$ & phase difference between stator and rotor d-axis \\
\hline$u_{g \_a b c}$ & instantaneous grid side voltage \\
\hline$u_{s_{-} a b c}$ & instantaneous stator voltage \\
\hline$u_{d c}$ & DC link voltage \\
\hline$u_{m e a s}$ & measured voltage \\
\hline$u_{r e f}$ & reference voltage \\
\hline$s$ & slip \\
\hline$i_{d r}$ & d-axis rotor current \\
\hline$i_{q r}$ & q-axis rotor current \\
\hline$P_{r e f}$ & reference power \\
\hline$i_{q g}$ & q-axis grid current \\
\hline
\end{tabular}

\section{Methodology}

This section describes the methods of grid voltage [12] recovery by controlling rotor side converter (RSC) and grid side converter (GSC). For this purpose, we have used proportional integral (PI) [3-7-10] controller that produce the output of comparator. During the fault there will be voltage dip (less than $0.9 \mathrm{pu}$ ) [5-9] which results in dynamic instability of power flow in the transmission line system. To recover the grid voltage, we have to inject the reactive power which will be injected both through RSC and GSC.

Here, the voltage is proportional to the reactive power in which the power is controlled both from RSC and GSC in [6-10]. The RSC controls the active (P) and reactive (Q) power whereas the GSC controls only the reactive $(\mathrm{Q})$ power in [10]. The active current component and reactive current component controls the active and reactive power respectively.

The proposed block diagrams of RSC and GSC controller are presented in Figures 4 and 5.

Both RSC and GSC consists of two loops. RSC consists of upper loop i.e. reactive power loop and lower loop i.e. active power loop. GSC consists of upper loop i.e. DC link voltage loop and lower loop i.e. reactive power loop. In above circuit, the current limiter limits the current for its specified limit. In GSC, PLL is responsible for the measurement of frequency that is used to convert the unsymmetrical components dq into symmetrical components abc. With the help of braking system. we can control the power generated from the DFIG.

\section{Model System}

Our main block diagram of the project is as shown in Figure 6. We have modeled the Figure 1 and Figure 3 with the help of Matlab Simulink model as shown in above figure. This figure includes the DFIG with control and braking system. In case of control parts, 


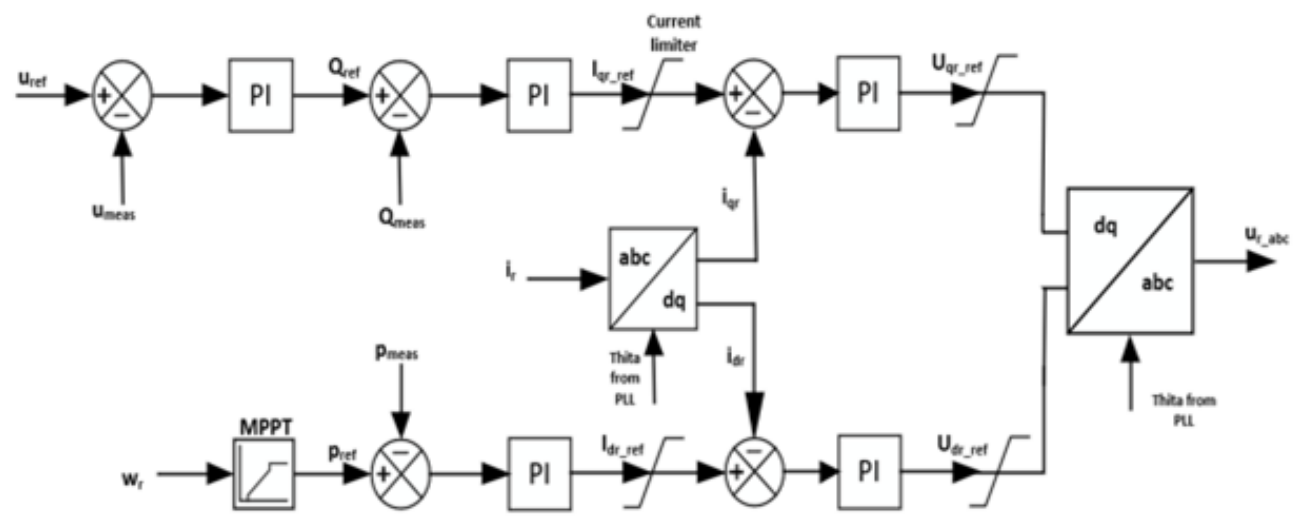

Figure 4: RSC controller

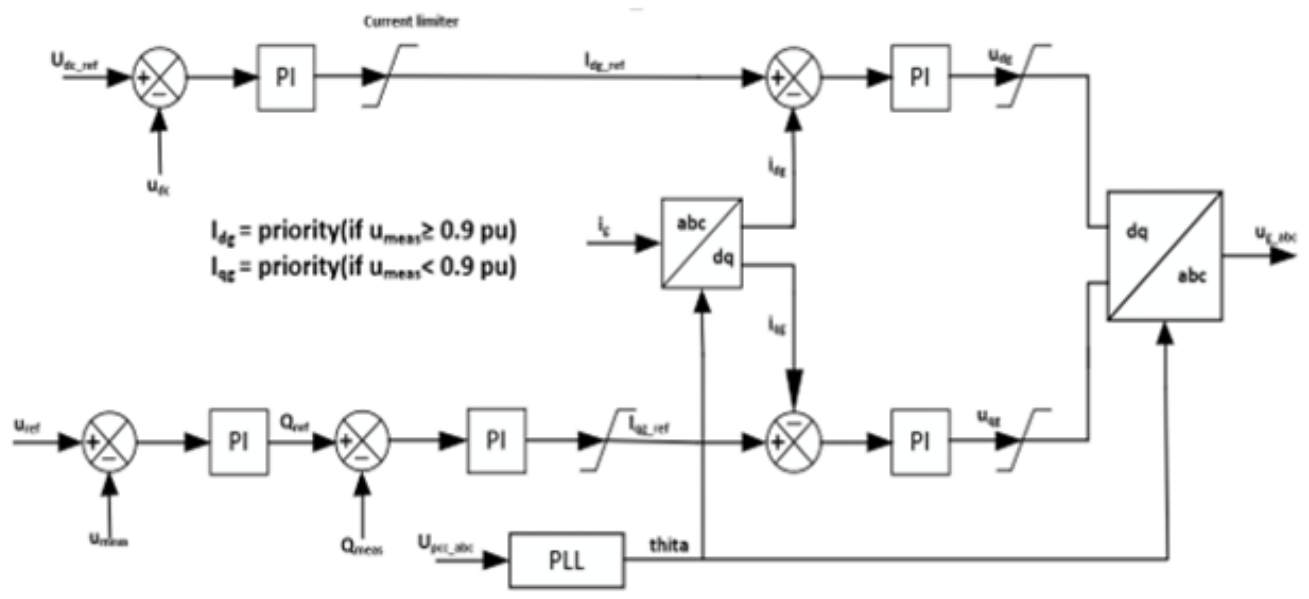

Figure 5: GSC controller

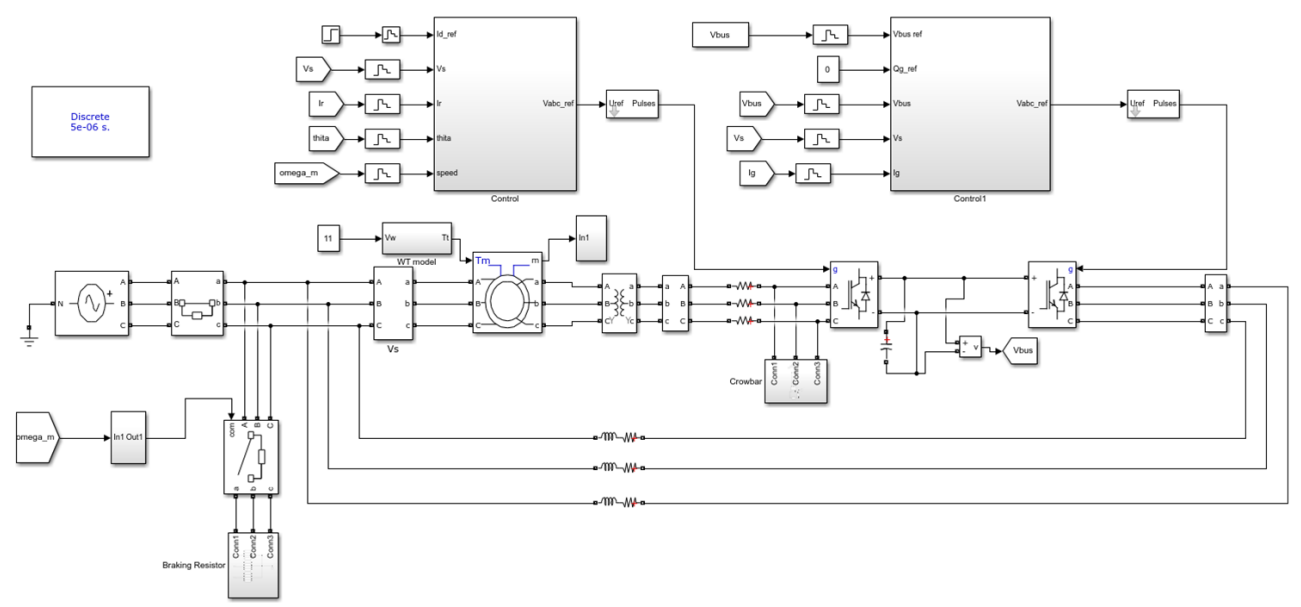

Figure 6: Main block of simulink model 
RSC and GSC controllers are being used, whereas for braking system braking resistors are used. These resistors are used to dissipate to the power during abnormal conditions. Different measurements units are used here. Here, grid voltage will be compared with the reference voltage and error signal is used as the control signal in case of converters. The braking system will be activated when the rotor speed exceeds its normal speed. Then, the power will be supplied to the braking resistors that will consume it. If there is condition of voltage dip then it will be controlled by the RSC and GSC controllers. And for that system run away condition, braking system will be activated.

The braking system, shown in Figure 7, mainly consists of braking resistors. Braking resistors are used to dissipate the power. With the help of this system, rotor speed is limited to its safe value.

For calculating the value of braking resistor in single phase, we have used the following formula:

$$
\text { Braking Resistor }=\frac{V^{2}}{p}
$$

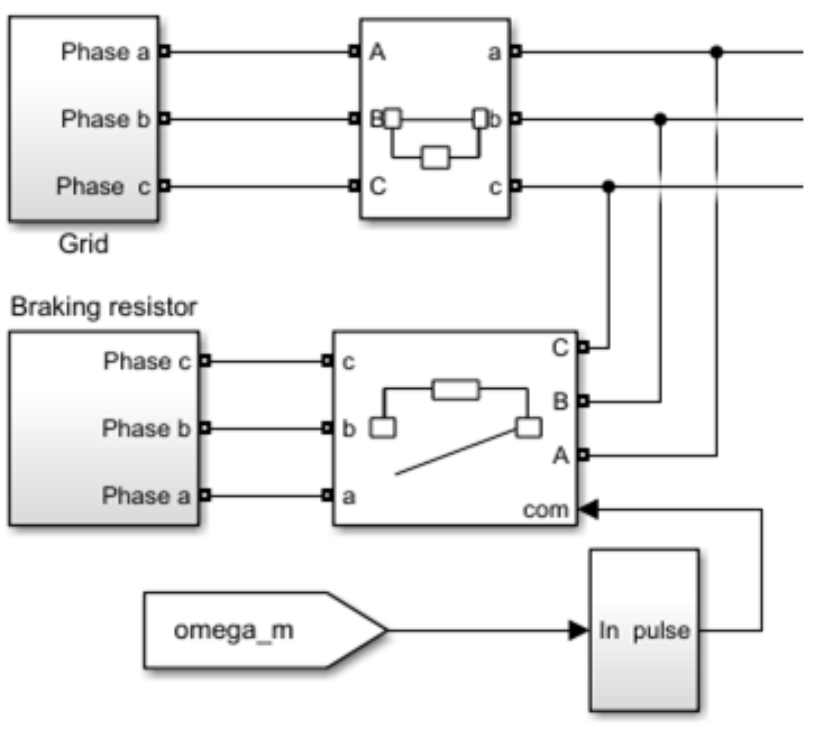

Figure 7: Braking System

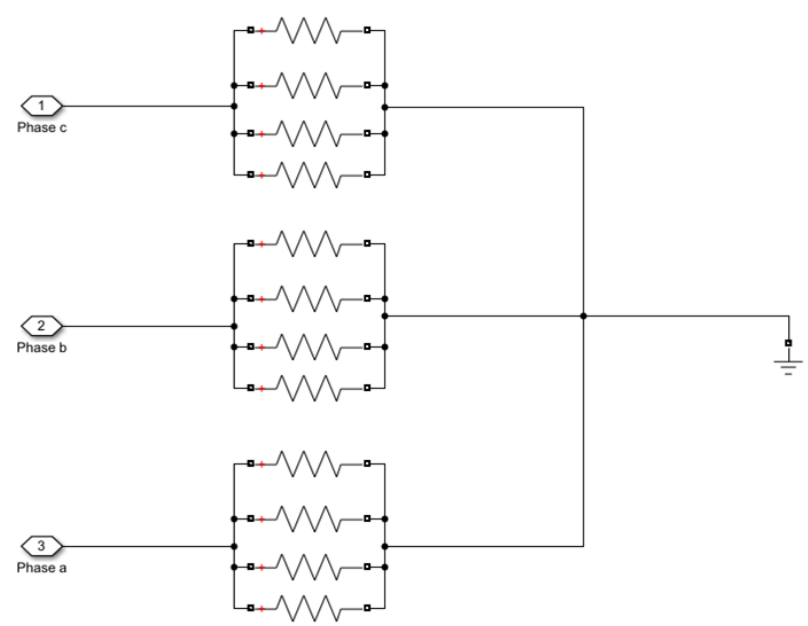

Figure 8: Design of braking resistor

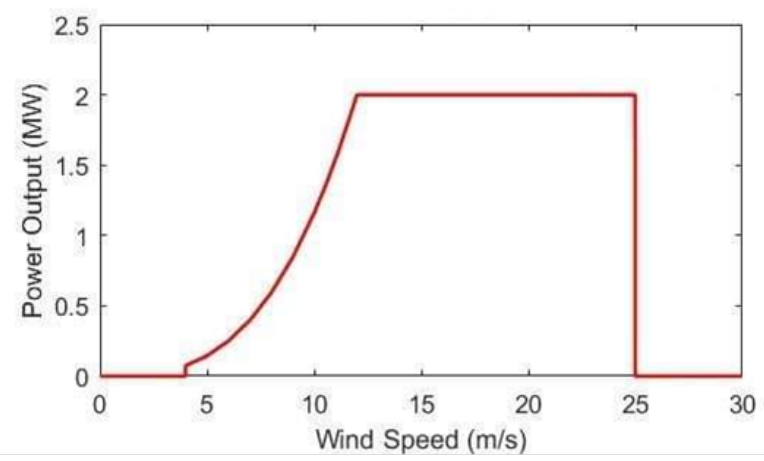

Figure 9: Power-wind speed curve for a 2 MW DFIG

Figure 9 is the power curve of 2 MW DFIG. Here, the rated speed is $12 \mathrm{~m} / \mathrm{s}$. The cut-in and cut-off wind speeds are $4 \mathrm{~m} / \mathrm{s}$ and $25 \mathrm{~m} / \mathrm{s}$ respectively.

\section{Simulation Results}

At $6 \mathrm{~s}$ a symmetrical voltage dip is simulated. The voltage dip lasts for $200 \mathrm{~ms}$, and then ramp recovery of voltage occurs as shown in Figure 10 and Figure 11 below. The system reaches steady state at $600 \mathrm{~ms}$, so any oscillations before that are neglected.

Again, at 10s, the symmetrical voltage dip is simulated and its results are shown below in Figure 12 and Figure 13.

Figures 10, 11, 12, and 13 shows that the voltage starts recovering after injecting the reactive power. As voltage is directly proportional to the reactive power, more voltage will be recovered depending on the rate of injection of reactive power. If the rate of injecting the 


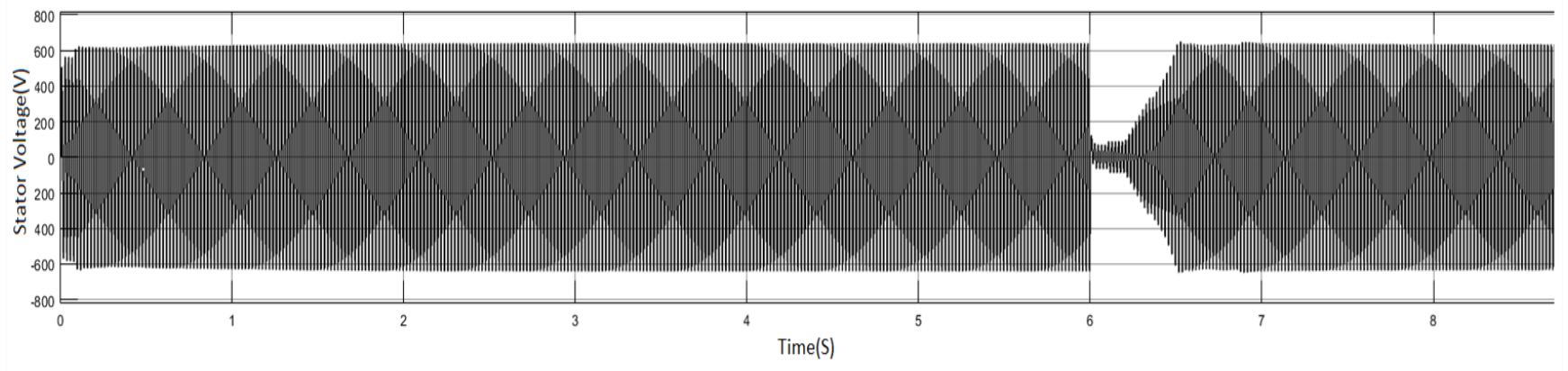

Figure 10: Stator voltage during its dip and recovery (normal)

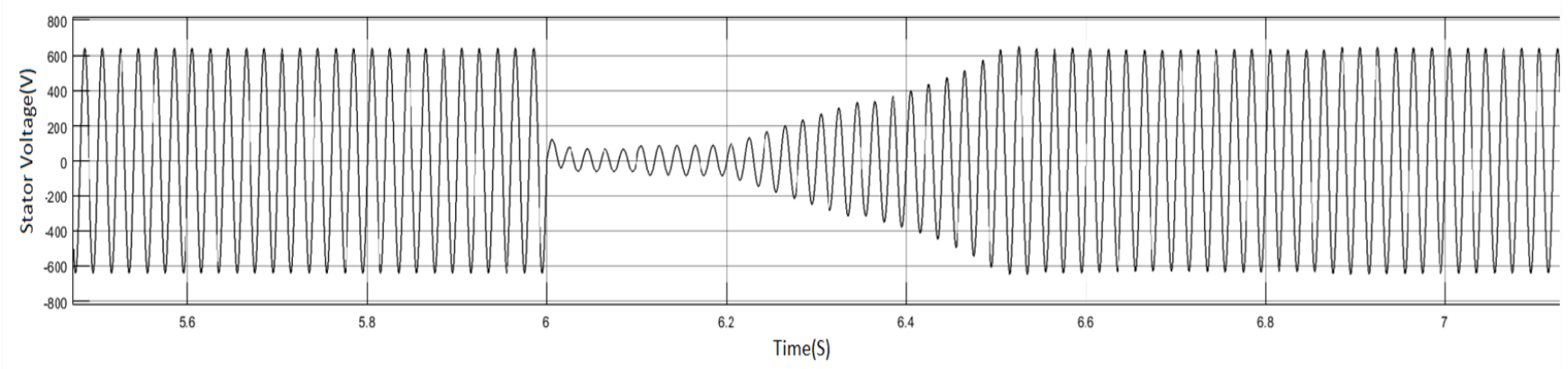

Figure 11: Stator voltage during its dip and recovery (zoom)

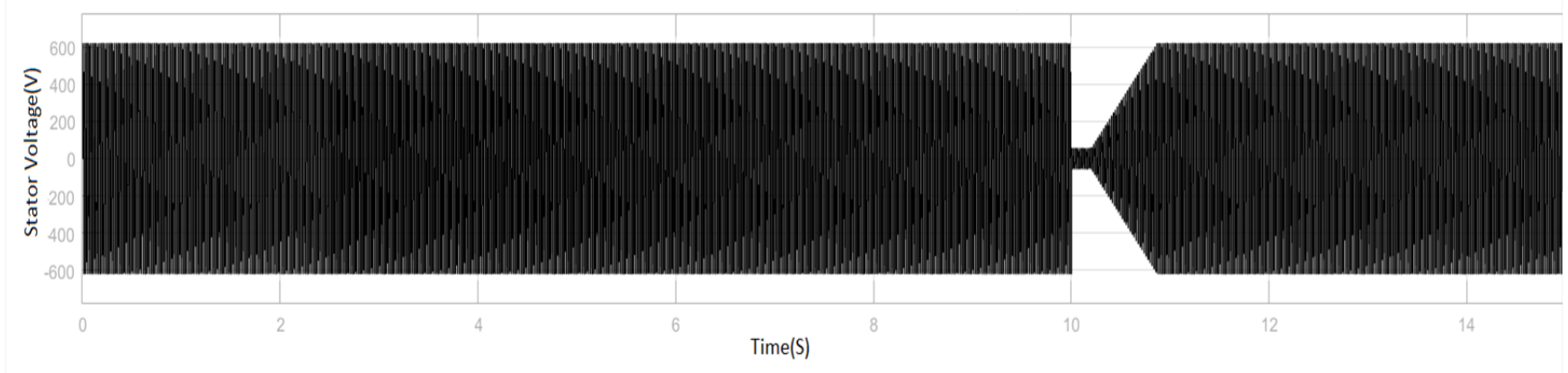

Figure 12: Stator voltage during its dip and recovery (normal)

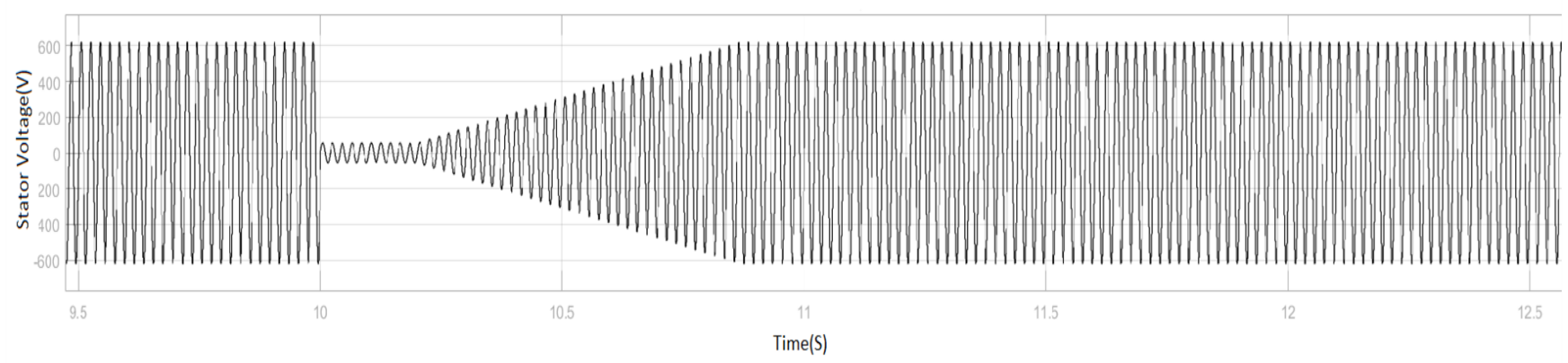

Figure 13: Stator voltage during its dip and recovery (zoom) 


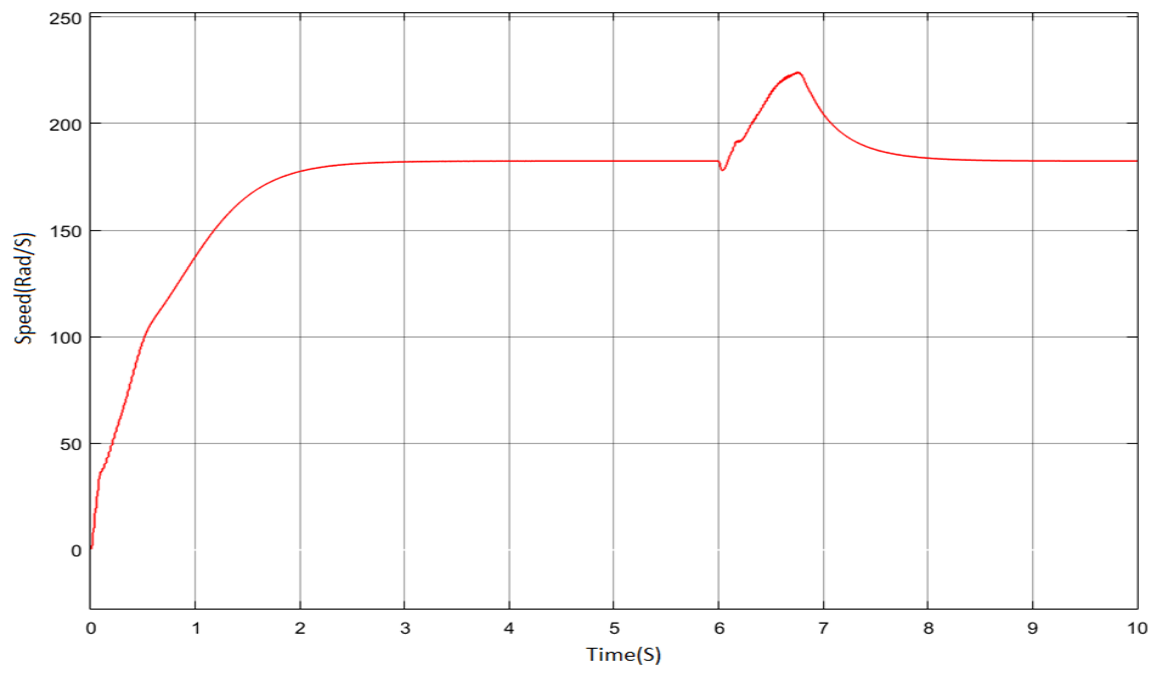

Figure 14: Rotor speed
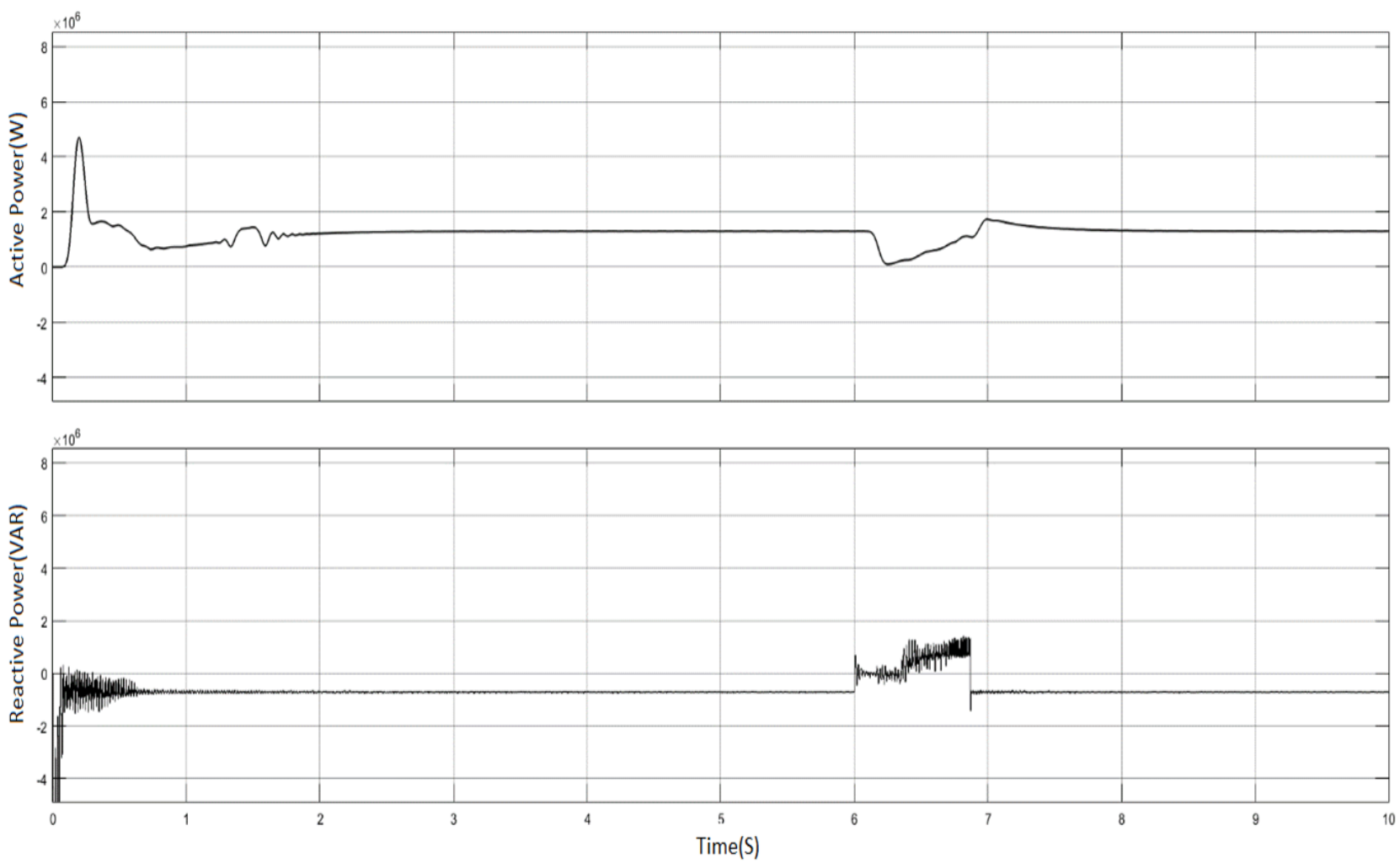

Figure 15: Active and reactive power of DFIG

reactive power is high then the voltage will be recovered as fast as its rate. The reactive power will be injected from the rotor and stator side of the DFIG. Both sides help in support of voltage recovery.

When DFIG is left unprotected, the rotor current rise by more than four times during voltage dip. Similarly, the dc link voltage rises by more than two times. This is very dangerous for the DFIG rotor circuit and converters, for safe operation the current should be within three times of nominal rotor current. During the fault, the rotor speed exceeds its normal speed. When the fault is clear, the speed lowers to its operating speed. As we know the power won't be consumed during the fault, so the speed 


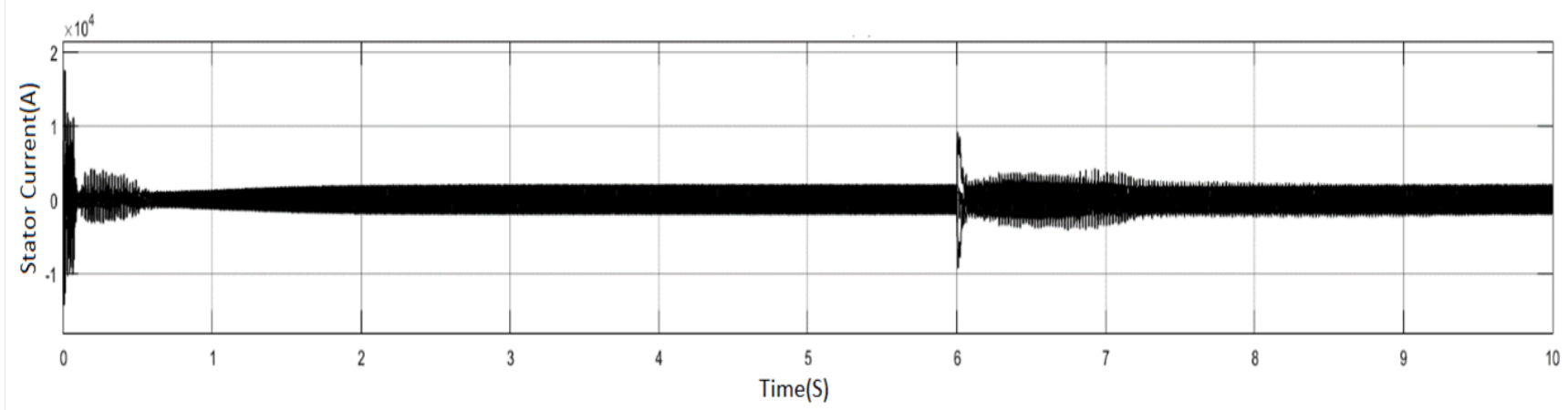

Figure 16: Waveform of stator current

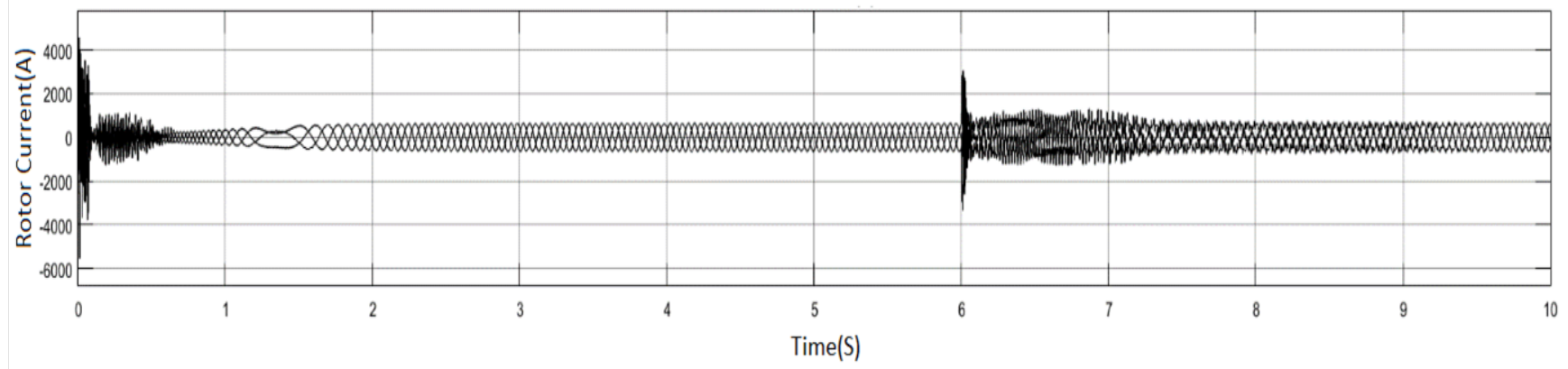

Figure 17: Waveform of rotor current

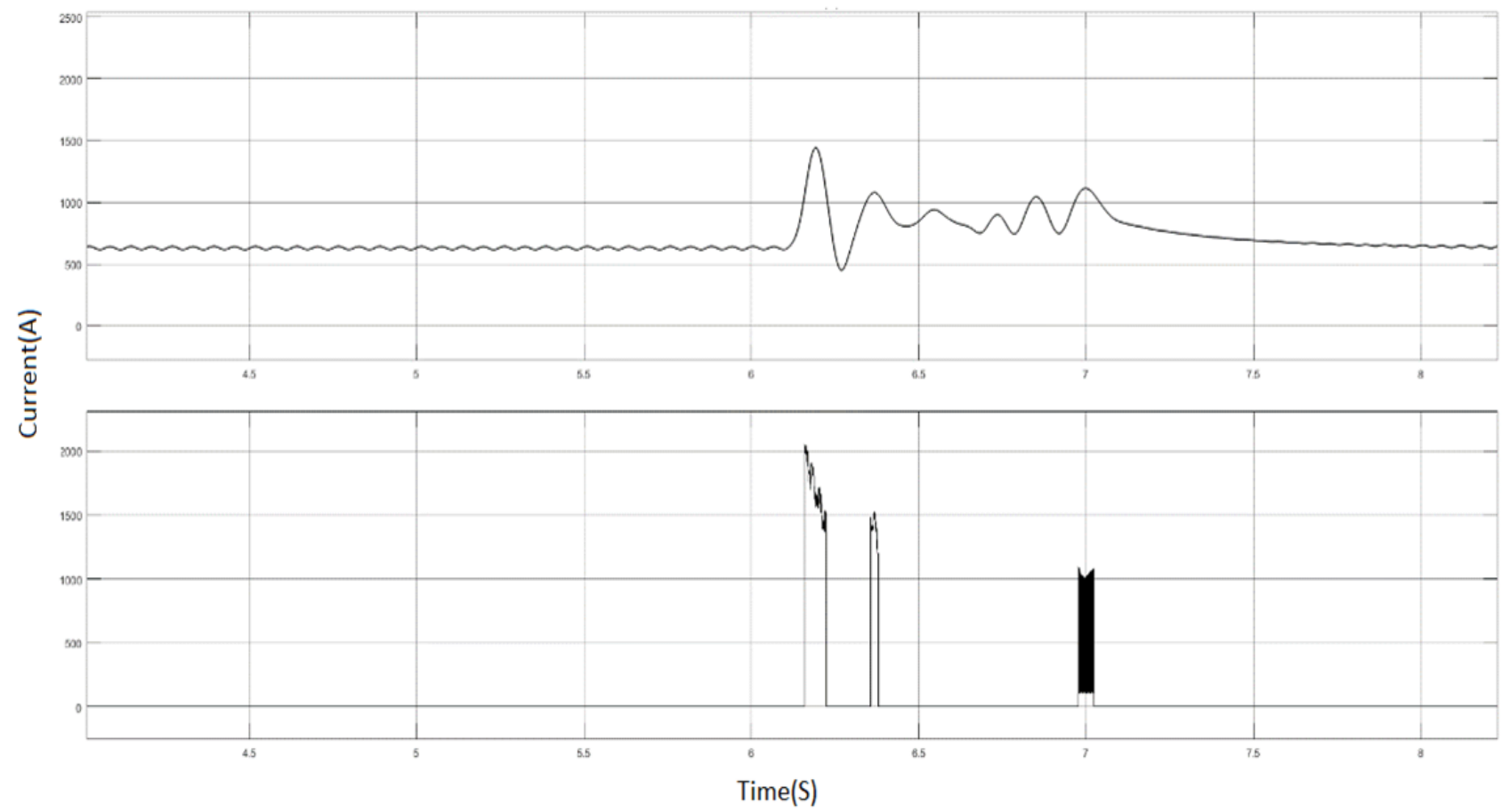

Figure 18: Rotor current and crowbar current with crowbar connected 


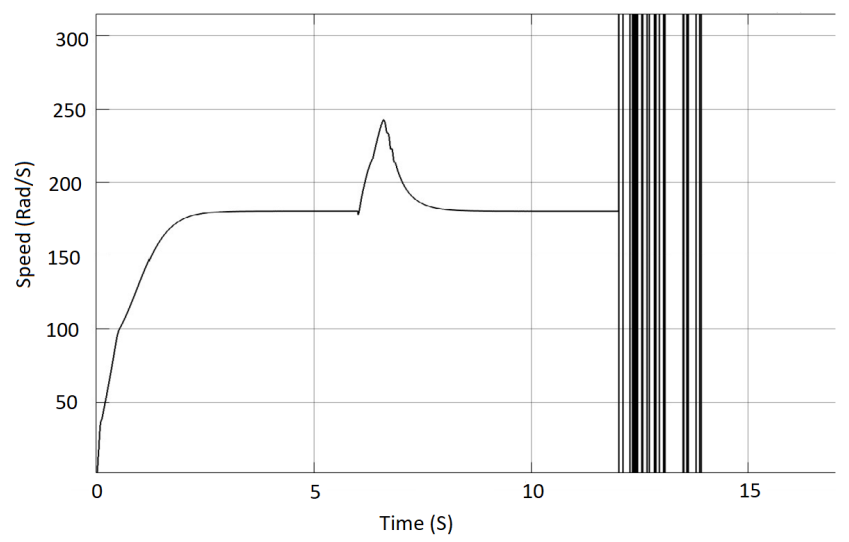

Figure 19: Rotor speed without braking system

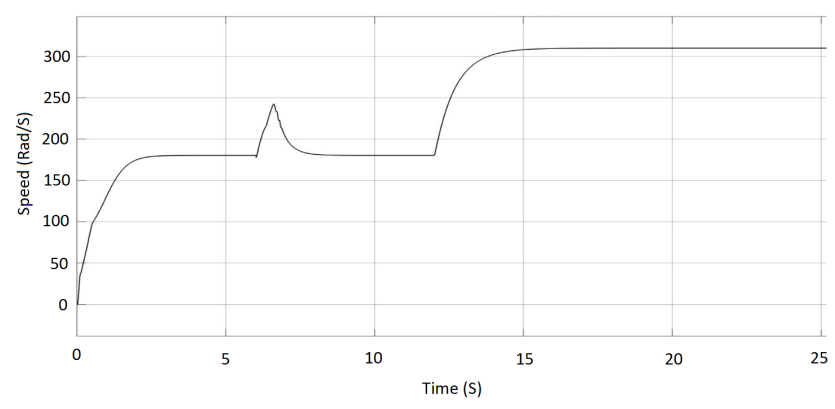

Figure 20: Rotor speed with braking system

will be increased due to no load condition. To control the rotor speed at its normal value, the voltage dip is cleared by injecting the reactive power from DFIG.

From Figure 15, we see that active power injected to grid by DFIG is reduced during voltage dip, and the reactive power injection is increased to support the grid voltage. The total power of the system has to be constant. So, the active power will be decreased and reactive power will be increased during the voltage dip condition to support the grid voltage. We have to inject more reactive power if the voltage dip is more and less reactive power for lower voltage. In corresponding to the voltage dip, the active power will be reduced as much as reactive power is increased.

From above figures, we can see that the rotor and stator current is suddenly increased during voltage dip. After and before the voltage dip the waveform is as normal as it should be.

Insertion of crowbar in the rotor circuit reduces the rotor surge current within the limit (less than three times of nominal current). From Figure 18, it can be seen that crowbar conducts whenever the rotor current is above the threshold value which verifies the working of our control strategy.

Figure 19 shows the waveform of rotor speed with time. Normally the rotor speed is 180 radian per second. During a voltage dip, rotor speed increases which comes back to normal condition after voltage support. Here, at 8 second a particular scenario of grid failure is introduced where the grid is opened. The rotor speed goes beyond its limitation which is a real problem and should be controlled as fast as possible.

To control the rotor speed, braking system is implemented where all the power generated is dropped in a braking resistor. From Figure 20, it can be seen that the rotor speed is only about 312 rps which is under acceptable limit. After controlling the speed under limit, mechanical braking can be used safely without high heating.

\section{Conclusion}

Here, the control scheme for voltage dip and braking system of a DFIG-based wind turbine that supports the grid voltage by using the PI controller in both RSC and GSC controller is expressed. In addition, the mechanical braking system is employed and in the case of the emergency the total power production from the DFIG wind turbine is dissipated in the dumped load after disconnecting the DFIG from the grid. The proposed control scheme allows voltage support ability of the DFIG by injecting reactive current capability during a fault. Hence with the help of PI controller, the voltage dip problem can be solved. Also, the braking system can be implemented with the help of braking resistors.

\section{References}

[1] A. Viswambharan, "Comparison of SCIG and DFIG Wind Turbines during Variable Wind Speed," International Journal of Innovative Research in Electrical, Electronics, Instrumentation and Control Engineering, vol. 4, 2016.

[2] Global Wind Energy Council, Global Wind Energy Outlook. 2018.

[3] G. Abad, J. Lopez, M. A. Rodríguez, et al., Doubly Fed Induction Machine: Modeling and Control for Wind Energy Generation. John Wiley \& Sons, Inc., 2011

[4] H. Abu-Rub, M. Malinowski, K. Al-Hadad, Power Electronics for Renewable Energy Systems, 
Transportation and Industrial Applications. John Wiley \& Sons, Inc, 2014.

[5] J. Kim, E. Muljadi, J. W. Park, and Y. C. Kang, "Flexible IQ-V Scheme of a DFIG for Rapid Voltage Regulation of a Wind Power Plant," IEEE Transaction on Industrial Electronics, 2017.

[6] J. Kim J, J. K. Seok, E. Muljadi, and Y. C. Kang, "Adaptive Q-V Scheme for the Voltage Control of a DFIG-Based Wind Power Plant," IEEE Transaction on Power Electronics, 2014.

[7] K. Thapa K and K. Jayasawal, "Pitch Control Scheme for Rapid Active Power Control of a PMSG-Based Wind Power Plant," IEEE Transactions on Industry Applications, doi: 10.1109/TIA.2020.3015169.

[8] K. Thapa K, G. Yoon, S. H. Lee, Y. Suh, and Y. C. Kang, "Dedicated cutback control of a wind power plant based on the ratio of command power to available power," Journal of Electrical Engineering and Technology, vol. 9, no. 3, pp. 835-842, 2014.
[9] K. Thapa, J. Kim, and Y. C. Kang, "Coordinated control for low voltage ride-through of a PMSG-based wind power plant," Journal of International Council on Electrical Engineering, vol. 6, no. 1, pp. 242-251, 2016.

[10] K. Thapa, K. Jayaswal K, and G. Marasini, "Rapid LVRT Control of a DFIG-Based Wind Power Plants Based on Adaptive IQ-V Characteristics," in IEEE Conference on Power Electronics, Drives and Energy System, 2018.

[11] M. Tsili and S. Papathanassiou, "A review of grid code technical requirements for wind farms," 2007.

[12] S. Foster, X. Lie, and B. Fox, "Coordinated control and operation of DFIG and FSIG based Wind Farms," in 007 IEEE Lausanne Power Tech., Lausanne.

[13] Y. Ling and X. Cai, "Rotor current dynamics of doubly fed induction generators during grid voltage dip and rise," Int. J. Elect. Power and Energy Syst., vol. 44, pp. 17-24, 2013. 
